\title{
Maternal impressions of the new 2019 canadian food guide
}

\author{
Palak Patel ${ }^{1}$, Cynthia Mannion ${ }^{1}$ \\ ${ }^{1}$ University of Calgary, Alberta, Canada
}

\begin{abstract}
Canada's new food guide was released on January 2019 following its predecessor Eating Well with Canada's Food Guide released in 2007. Major changes in the new food guide included a partitioned plate of real foods, messages around healthy eating being more than the foods you eat, and no feature of the milk and alternatives group. There were also no recommended servings for age groups or developmental stages including pregnant women. The purpose of this qualitative study was to explore the perceptions of pregnant Canadian women toward the new Canada food guide. Eight pregnant women over the age of eighteen were recruited from facilities that offered prenatal fitness. Interviews included documenting impressions of the Canada food guide, dietary choices during pregnancy and planned dietary changes. The interviews were digitally recorded, and transcribed verbatim. Braun and Clarke thematic analysis was used to analyze the data. All the participants were familiar with Canada food guides and all but three were aware of the newest version. Participants commented that the new food guide was appealing and healthy. Most participants had already made changes to their daily diet that coincidentally corresponded to the new food guide. Many also followed the messages in the new food guide but reported that pregnancy was the main influence for food changes. Participants included more fruits and vegetables, and less meat than when they were not pregnant. The internet, family, physicians and previous knowledge were also used to inform food choices. Much of this information was however reported as too little and contradictory. Participants wanted information more specific to pregnant women which was not included in the new food guide. Canada's new food guide reinforced actions that women were already taking to improve their diet during pregnancy. The new food guide offers broad recommendations for Canadians to follow but pregnant women prefer a guide that is specific with clear recommendations for pregnant women.
\end{abstract}

Cite as: Patel P. and Mannion C. 2019. Maternal impressions of the new 2019 Canadian Food Guide. Alberta Academic Review, Vol 2 (3) 5, CASCH Special Issue (not peer-reviewed), DOI: 10.29173/aar86. 